\title{
Improvement of butyrylcholinesterase enzyme inhibition and medicinal properties of extracts of Aristotelia serrata leaves by ultrasound extraction
}

\author{
Hafiz Majid ${ }^{a, b, *}$, Filipa V.M. Silva ${ }^{a, c, *}$ \\ a Chemical and Materials Engineering Department, University of Auckland, Private Bag 92019, Auckland 1142, New \\ Zealand \\ b Faculty of Science and Natural Resources, Universiti Malaysia Sabah, 88400 Kota Kinabalu, Sabah, Malaysia \\ c LEAF, Instituto Superior de Agronomia, Universidade de Lisboa, Tapada da Ajuda, 1349-017 Lisboa, Portugal
}

\section{A R T I C L E I N F O}

\section{Article history:}

Received 28 April 2020

Received in revised form 3

September 2020

Accepted 12 October 2020

Available online 17 October 2020

Keywords:

Plant extracts

Ultrasound extraction

Optimization

Yield

Antioxidant activity

Alzheimer's Disease

\begin{abstract}
A B S T R A C T
Aristotelia serrata, wineberry, or makomako, is a small deciduous fast-growing shrub of New Zealand that produces a berry. In this study leaf extracts were produced using ultrasound technology. Alzheimer's Disease is a progressive mental deterioration related with ageing and senility, in which approved drugs for treatment inhibit butyrylcholinesterase (BChE), an enzyme present in the human brain. The ultrasound assisted extraction of natural anti-butyrylcholinesterase and antioxidants from this plant, and the yield of extraction were optimized using response surface methodology. The effect of acoustic power density (0.13-0.65 W/mL), time (1-20 min), and ethanol concentration (20-80\%) on BChE inhibition, antioxidant activity, and extraction yield was determined, the optimum extraction conditions being $0.53 \mathrm{~W} / \mathrm{mL}, 17.12 \mathrm{~min}$ and $74 \%$ ethanol. The optimized extracts were produced to experimentally validate the predicted responses. The $\mathrm{IC}_{50}$ concentrations were experimentally determined $(26.2 \mu \mathrm{g} / \mathrm{mL}$ for BChE, $5.5 \mu \mathrm{g} / \mathrm{mL}$ for radical scavenging activity). A. serrata leaf extracts have potential to be used as complements to medicines traditionally used for memory dysfunction.
\end{abstract}

(c) 2020 Institution of Chemical Engineers. Published by Elsevier B.V. All rights reserved.

\section{Introduction}

Neurodegeneration is characterized by gradual loss of neurons which leads to memory impairment (Dubey and Chinnathambi, 2019). Among all types of neuronal disorders in the elderly population, Alzheimer's Disease (AD) is the most common disease. The disease is highly associated with age, with $3 \%$ of patients belonging to $65-74$ age group, $18.7 \%$ of patients are between $75-84$, while as high as $47.2 \%$ of patients are above 85 years old (Markesbery, 1997). With the ageing society, it is estimated that the global prevalence of dementia will increase from 24.3 million in 2005 to 81.1 million in 2040 (Ma et al., 2019). AD is the third main cause of death behind car- diovascular and cancer in developed countries (Huang et al., 2016). Although it is known that AD is caused by genetic and other environmental factors, the pathogenesis and mechanism behind $A D$ remains unclear. One of the pathological features proposed includes the formation of amyloid plaques, neurofibrillary tangles, oxidative stress, and neuroinflammation. The main treatments for $\mathrm{AD}$ patients are cholinesterase inhibitors such as donepezil, galantamine and rivastigmine. Acetylcholinesterase (AChE) and butyrylcholinesterase (BChE) are the two brain enzymes targeted by these drugs. Initially AChE enzyme inhibitors were employed to treat patients. It

\footnotetext{
* Corresponding authors at: Universiti Malaysia Sabah (Malaysia) and University of Lisbon (Portugal).

E-mail addresses: hafizam@ums.edu.my (H. Majid), filipavinagresilva@gmail.com, fvsilva@isa.ulisboa.pt (F.V.M. Silva). https://doi.org/10.1016/j.fbp.2020.10.004

0960-3085/@ 2020 Institution of Chemical Engineers. Published by Elsevier B.V. All rights reserved.
} 
was later demonstrated that changes in the levels of BChE enzyme are also associated with the progression of $\mathrm{AD}$, especially in later stages of the disease (Farlow, 2002). As AD progresses, AChE levels decrease while BChE becomes the predominant cholinesterase in the brain. Hence, the inhibition of BChE activity may retard the formation of senile plaques (Schelterns and Feldman, 2003). It is believed that specific BChE inhibitors should improve the condition of patients with advanced AD, with fewer side effects (Giacobini, 2001; Greig et al., 2001; Pajk et al., 2020).

Aristotelia serrata, also known as wineberry or makomako, is a small tree found throughout the south island and lower north island of New Zealand (Saxton, 2008). The A. serrata leaves have been medicinally used as a decoction or infusion for treatment of burns, sore eyes, and rheumatism (Brooker and Cooper, 1961). Several chemical compounds have been identified from the roots, stems, and leaves of A. serrata: major alkaloid aristoteline and some minor alkaloids of aristoserratine, aristotelinone, serratenone, makomakine, aristoserratenine, aristomakine, serratoline, isohobartine, aristomakinine, isosorelline, and tasmanine (Saxton, 2008). Interestingly, screening studies with this plant revealed that $1000 \mu \mathrm{g} / \mathrm{mL}$ of methanol and ethyl acetate extracts from Aristotelia serrata leaves presented $>90 \%$ inhibition of BChE enzyme activity (Majid and Silva, 2020). Since most of the AChE inhibitors are known to contain nitrogen (Orhan et al., 2004), the high BChE inhibitory activity A. serrata extract may also be related to its rich nitrogen alkaloidal content.

Extraction is the first step in the separation of medically active portions from plant matrices (Tiwari et al., 2011). The ideal extraction method must be sustainable, economically viable, and must be performed as efficiently as possible (Apel et al., 2020). Ultrasound assisted extraction (UAE) treatment has been known to increase extraction efficiency of bioactive compounds such as alkaloids from various plant materials (Hossain et al., 2014; Rambo et al., 2019). The sonication facilitates higher recoveries of bioactive compounds from plant materials as a result of the cavitation phenomena, mechanical agitation and thermology (Chakraborty et al., 2020). Increased yield of extraction, higher extraction rate/quicker extraction, and the use of clean, green solvent with improved performance are other advantages of ultrasound extraction. The optimization of the extraction process conditions leads to maximum efficacy of extraction. Response surface methodology (RSM) is a statistical method for developing, improving and optimizing processes involving several variables (Liu et al., 2000; Chakraborty et al., 2020). The rationale behind RSM application is to reduce the number of experiment trials needed for the study of multiple variables, which is not possible using the conventional one factor at a time optimization method. RSM also generates useful mathematical models to predict responses for different extraction conditions. The main objective of this study was to use RSM to estimate the optimal conditions of UAE parameters acoustic power density $(A)$, extraction time $(t)$ and ethanol concentration (E) to obtain the highest BChE inhibition, antioxidant activity (expressed as DPPH radical scavenging activity, RSA), and yield. Mathematical models for prediction of BChE inhibition, DPPH RSA, and extraction yield as a function of extraction parameters were also generated and validated. The specific objectives were: 1 . To select the best solvent and appropriate range of extraction parameters to extract anti-butyrylcholinesterase (BChE) compounds from A. serrata leaves; 2 . To study the effect of acoustic power density, extraction time, and ethanol concentration on BChE inhibition using response surface methodology; 3. To experimentally validate the optimum extraction conditions; 4. To determine the $\mathrm{IC}_{50}$ concentrations for $\mathrm{BChE}$ inhibition and DPPH RSA of the optimized extracts.

\section{Material and methods}

\subsection{Plant materials and chemicals}

Dried Aristotelia serrata leaves were purchased from a local plant supplier "Kiwi Plants Ltd", Wellington, New Zealand (https://www.kiwiplants.co.nz). The material was ground into fine particles using a grinder and sifted through a $0.25 \mathrm{~mm}$ sieve to obtain a uniform particle size. The material was then vacuum-sealed and stored in a dark condition at room temperature until use in the extraction experiments (Adewusi and Steenkamp, 2011).

Methanol and ethyl acetate were of chromatography grade and obtained from ECP (ECP laboratory research and chemicals, New Zealand). Ethanol and acetone were purchased from ECP and of analytical grade. The chloroform was of analytical grade and was obtained from Sigma-Aldrich (NZ). The following reagents were needed for enzyme or DPPH RSA analysis: phosphate buffer, potassium hydroxide, 5,5'-dithiobis-(2-nitrobenzoic acid) (DTNB), sodium hydrogen carbonate, butyrylthiocholine iodine substrate (BTchI) butyrylcholinesterase from human serum (BChE), dimethyl sulfoxide, 2,2-diphenyl-1-picrylhydrazyl (DPPH). Eserine (phystogmine) and ascorbic acid standards were purchased from Sigma-Aldrich (NZ). Deionised water was used for all experiments.

\subsection{Ultrasound assisted extraction}

One gram of dried and grounded A. serrata leaves was extracted using a fixed ratio of $20 \mathrm{mg}$ plant/mL solvent in a beaker containing $50 \mathrm{~mL}$ of solvent, which was submerged in an ice water bath for temperature control. The process of ultrasonic extraction was performed by using a UP200S (24 $\mathrm{kHz}$ frequency) ultrasonic processor fitted with the sonotrode S3 - micro tip 3, with $3 \mathrm{~mm}$ diameter (Hielscher Ultrasonics $\mathrm{GmbH}$, Teltow, Germany). This was dipped about halfway into the beaker containing the mixture of plant leaves + solvent. The maximum acoustic energy density for this specific sonotrode is $460 \mathrm{~W} / \mathrm{cm}^{2}$ according to the specifications of the manufacturer manual (Hielscher, 2007). The area of $3 \mathrm{~mm}$ tip is $0.0707 \mathrm{~cm}^{2}$, so a value of $32.5 \mathrm{~W}$ was determined for the acoustic power at the maximum amplitude of $210 \mu \mathrm{m}$ allowed for this sonotrode. For a mixture volume of $50 \mathrm{~mL}(+1 \mathrm{~g})$ the calculated maximum acoustic power density is $0.65 \mathrm{~W} / \mathrm{mL}$. The power/energy input was configured by setting the amplitude of the sonicator probe, as higher amplitude is proportional to higher energy.

Prior to each experiment, the temperature of the extraction solvent inside the beaker was stabilized at the experiment's set temperature, then the dry A. serrata leaves were added and sonication started. During sonication, the extraction temperature was continuously controlled with a digital thermometer dipped in the mixture and kept approximately constant $( \pm 2$ ${ }^{\circ} \mathrm{C}$ ) by adding ice water to the bath surrounding the beaker containing the extraction mixture. 


\subsection{Preparation of plant extract and determination of extraction yield}

Following the extraction, samples of solvent containing the crude extract were filtered (Whatman n. 1 filter paper) to obtain a clear extract solution and remove solid residues of the plant. Then the clear solution was dried at $50^{\circ} \mathrm{C}$ under vacuum using a rotary evaporator (Rotavapor R-215, BÜCHI Labortechnik AG, Flawil, Switzerland) to remove the solvent and obtain the crude extract. The extracts were then further air-dried in a fume hood at room temperature until constant weight was obtained. The final weight of the dried crude extract was recorded for the determination of extraction yield, and then stored at $-20^{\circ} \mathrm{C}$ for further analysis. The yield of extraction in percentage of extraction was calculated as follows:

Extraction yield $(\%)=\frac{\text { weight of dried crude extract }(g)}{\text { weight of makomako leaves powder }(g)}$

$\times 100$

\subsection{Overview of experiments}

The optimization of ultrasound assisted extraction (UAE) from A. serrata leaves was performed in two stages. The first stage 2.5 involved the selection of appropriate extraction solvent and the identification of variables with a significant effect on the extraction yield, BChE inhibition and RSA. For this set of experiments, the effects were analysed by changing one factor at a time, while keeping the other variables constant: 0.52 $\mathrm{W} / \mathrm{mL}$ of acoustic power density - A, $50^{\circ} \mathrm{C}$ of temperature $\mathrm{T}, 10$ min extraction time $-\mathrm{t}$ (except the experiment testing different types of solvents in which extractions were carried out for $20 \mathrm{~min}$ ), 50\% ethanol-water solvent.

In the second stage of experiments, further optimization of extraction conditions 2.6 was carried out through response surface methodology (RSM) using a Box-Behnken experimental design to investigate the simultaneous effect of $\mathrm{A}(0.13-0.65 \mathrm{~W} / \mathrm{mL}), \mathrm{t}(1-20 \mathrm{~min})$ and $\mathrm{E}(20-80 \%)$ on plant extraction yield (\%), BChE inhibition (\%) and antioxidant activity assessed by DPPH radical scavenging activity (RSA, \%). Based on the results of first stage experiments, a fixed temperature of $50{ }^{\circ} \mathrm{C}$ was used in all other ultrasound extraction experiments.

Lastly in the third stage of experiments optimized conditions predicted by the models for maximum inhibition of $\mathrm{BChE}$ and RSA were tested experimentally and the experimental IC 50 concentrations were determined for extracts produced in those conditions.

\subsection{The effect of different ultrasound extraction parameters on BChE inhibition, RSA and yield of A. serrata extracts}

\subsubsection{Testing different solvents for extraction}

Five different solvent types of acetone, chloroform, ethyl acetate, methanol, and ethanol at $100 \%$ concentration were assayed. One gram of dried and ground A. serrata leaves were extracted in a beaker containing $50 \mathrm{~mL}$ of each solvent. The extraction was performed for $20 \mathrm{~min}$ at $50{ }^{\circ} \mathrm{C}$, using A of 0.52 $\mathrm{W} / \mathrm{mL}$.
2.5.2. Ethanol concentration in water (E)

Mixtures of ethanol-water were selected as extraction solvents. The final concentrations of ethanol in water (E) were $0 \%$, $30 \%, 50 \%, 80 \%$ and $100 \%$. Dried and ground A. serrata leaves $(1$ g) were extracted with the $50 \mathrm{~mL}$ of solvent. All the extractions were performed for $10 \mathrm{~min}$ at $50^{\circ} \mathrm{C}$, with a of $0.52 \mathrm{~W} / \mathrm{mL}$. The samples were filtered and freed of solvent by rotary evaporation. The crude extracts were stored then stored at $-20^{\circ} \mathrm{C}$ prior to analysis.

\subsubsection{Extraction temperature}

A. serrata leaves were extracted at different temperatures of 30 , $40,50,60$, and $70{ }^{\circ} \mathrm{C}$. One gram of dried A. serrata leaves were sonicated with $50 \mathrm{~mL}$ of $50 \%$ ethanol solvent for $10 \mathrm{~min}$ using a ultrasound power (A) of $0.52 \mathrm{~W} / \mathrm{mL}$. The samples were filtered and evaporated to dryness by using a rotary evaporation. The crude extracts were stored at $-20^{\circ} \mathrm{C}$ prior to analysis.

\subsubsection{Extraction time (t)}

Extraction of A. serrata leaves were executed for a time ranging from 2 to $60 \mathrm{~min}$, in the proportion of $1 \mathrm{~g}$ of dried plant leaves for $50 \mathrm{~mL}$ of $50 \%$ ethanol. The extraction was done at $50{ }^{\circ} \mathrm{C}$ using A of $0.52 \mathrm{~W} / \mathrm{mL}$. The samples were filtered and dried by rotary evaporation to obtain crude extracts. The crude extracts were stored at $-20^{\circ} \mathrm{C}$ prior to analysis.

\subsubsection{Acoustic power density (A)}

Extraction sonication experiments were performed at settings of $0.13,026,0.39,0.52$, and $0.65 \mathrm{~W} / \mathrm{mL}$. Dried A. serrata leaves $(1 \mathrm{~g})$ were extracted with $50 \%$ ethanol at different A ultrasonic powers. The extraction was performed for $10 \mathrm{~min}$ at $50{ }^{\circ} \mathrm{C}$. The samples were filtered, dried using rotary evaporation, and crude dried extracts were then stored at $-20^{\circ} \mathrm{C}$ until analysis.

\subsubsection{Response surface methodology to further} investigate the combined effect of acoustic power density, time, and ethanol concentration on BChE inhibition, RSA and extraction yield: experimental design, optimization and experimental validation of model predictions

The extraction parameters were further optimized using RSM based on a three level, three variables Box Behnken Design (BBD). Acoustic power density (A, $\mathrm{W} / \mathrm{mL})$, time (t, min), and ethanol concentration in water $(\mathrm{E}, \%)$ were the independent variables optimized for the extraction of A. serrata leaves, while the dependent variables were BChE inhibition (\%), DPPH radical scavenging activity RSA (\%), and yield of extraction (\%). The $\mathrm{A}$ of 0.13 to $0.65 \mathrm{~W} / \mathrm{mL}$, t between 1 to $20 \mathrm{~min}$, and $\mathrm{E}$ in water from 20 to $80 \%$ were investigated. The coded levels -1 and +1 are the lower and higher limits of the variable in the range studied, and 0 is the midpoint for each variable $(0.39 \mathrm{~W} / \mathrm{mL}, 10.5 \mathrm{~min}$ of extraction time and $50 \%$ ethanol). The complete experimental design is composed by 17 experimental points, including five replicates of the midpoint that were used for estimation of pure error sum of squares (Table 1). Each experimental condition was performed in triplicates $(n=$ 3) and average values \pm SD (standard deviation) were taken as response for the dependent variable. For each of the 3 responses, all data were fitted into a quadratic polynomial equation.

The experimental results were analysed using DesignExpert Version 12 software (Trial version, Stat-Ease Inc., Minneapolis, MN, USA). Analysis of variance (ANOVA) was then carried out for each response to determine the statistical significance and suitability of the model. The significances 
Table 1 - Experimental results of Box Behnken design used to investigate the effect of acoustic power density, extraction

time, and ethanol concentration on butyrylcholinesterase (BChE) Alzheimer enzyme inhibition, radical scavenging

activity (RSA) and yield of Aristotelia serrata leaf extracts produced.*

\begin{tabular}{|c|c|c|c|c|c|c|}
\hline Run & $\begin{array}{l}\text { A, Acoustic } \\
\text { power density } \\
(\mathrm{W} / \mathrm{mL})\end{array}$ & $\mathrm{t}$, Time (min) & $\begin{array}{l}\text { E, Ethanol } \\
\text { concentration } \\
(\%)\end{array}$ & $\begin{array}{l}\text { BChE } \\
\text { inhibition }^{a} \\
(\%)\end{array}$ & $\begin{array}{l}\text { DPPH RSA } \\
\text { (\%) }\end{array}$ & Yield (\%) \\
\hline 1 & 0.39 & 1 & 80 & 44.57 & 55.46 & 42.86 \\
\hline 2 & 0.39 & 10.5 & 50 & 59.6 & 65.45 & 52.34 \\
\hline 3 & 0.39 & 10.5 & 50 & 66.92 & 61.85 & 54.38 \\
\hline 4 & 0.39 & 20 & 20 & 38.49 & 49.35 & 35.52 \\
\hline 5 & 0.13 & 1 & 50 & 62.25 & 53.87 & 38.35 \\
\hline 6 & 0.39 & 10.5 & 50 & 58.48 & 61.87 & 52.87 \\
\hline 7 & 0.65 & 10.5 & 80 & 78.28 & 69.35 & 54.46 \\
\hline 8 & 0.65 & 1 & 50 & 54.83 & 65.86 & 44.56 \\
\hline 9 & 0.39 & 10.5 & 50 & 68.68 & 60.35 & 48.26 \\
\hline 10 & 0.39 & 1 & 20 & 32.85 & 48.54 & 28.58 \\
\hline 11 & 0.39 & 10.5 & 50 & 65.53 & 60.49 & 51.63 \\
\hline 12 & 0.65 & 10.5 & 20 & 51.87 & 53.35 & 38.49 \\
\hline 13 & 0.65 & 20 & 50 & 76.45 & 70.46 & 52.95 \\
\hline 14 & 0.13 & 20 & 50 & 48.85 & 60.65 & 43.53 \\
\hline 15 & 0.13 & 10.5 & 80 & 58.84 & 63.49 & 48.57 \\
\hline 16 & 0.39 & 20 & 80 & 72.43 & 69.53 & 58.35 \\
\hline 17 & 0.13 & 10.5 & 20 & 25.84 & 53.88 & 40.58 \\
\hline
\end{tabular}

*Temperature of extractions $50^{\circ} \mathrm{C}$.

a Range of standard deviation $(\%)=(2.13-8.11)$.

b Range of standard deviation $(\%)=(1.59-8.64)$.

c Range of standard deviation $(\%)=(1.89-7.95)$.

of all terms were analysed by F-value and $p$-value $(p<0.05)$, while the quality of the equation models was expressed by the adjusted coefficient of determination $\left(R^{2}\right)$. The relationship between the dependent and independent variables was also presented using response surface plots.

To obtain optimum extraction (factors) conditions, the 3 responses (BChE inhibition, DPPH RSA, yield) were set to "maximum" to achieve the highest value, while the factors (acoustic power density, time, ethanol concentration) were set within the ranges investigated in the RSM study. The optimum extraction conditions were estimated by using the point prediction post analysis tool of Design Expert statistical software. Then those predicted values were compared to response values experimentally obtained for those extraction conditions. The $\mathrm{IC}_{50}$ values of the crude extracts and reference compounds with respect to their $\mathrm{BChE}$ inhibition and RSA were also determined.

\subsection{Enzyme inhibition and DPPH radical scavenging activity}

\subsubsection{Butyrylcholinesterase activity and inhibition}

The assay for measuring BChE activity was measured by the microplate assay using Ellman's colorimetric method and modified by Rauter et al. (2007). A. serrata extract mixtures were diluted with $12.5 \%$ DMSO-water and prepared in the concentration of $4.4 \mathrm{mg} / \mathrm{mL}$ which gives a final test concentration of $100 \mu \mathrm{g}$ of extract $/ \mathrm{mL}$. Physostigmine is a known BChE inhibitor compound and was used as a reference for comparison purposes.

Reagents were prepared as follows: $0.1 \mathrm{M}$ phosphate buffer was freshly prepared before each analysis (136.1 mg of $\mathrm{KH}_{2} \mathrm{PO}_{4}$ in $10 \mathrm{~mL}$ water, adjusted at $\mathrm{pH} 8.0$ with $\mathrm{KOH}) ; 0.01 \mathrm{M}$ DTNB solution (3.96 mg DTNB in $1 \mathrm{~mL}$ water containing 1.5 mg sodium hydrogen carbonate). $0.022 \mathrm{M}$ butyrylthiocholine iodide (BTChI) solution (7.0 mg BTChI in $1 \mathrm{~mL}$ water); 0.44
Unit/mL BChE solution (2.9762 mg of BChE enzyme in 6.746 $\mathrm{mL}$ buffer at $\mathrm{pH}$ 8.0).

The assay was achieved by adding $5 \mu \mathrm{L}$ of A. serrata extract, $200 \mu \mathrm{L}$ phosphate buffer, $5 \mu \mathrm{L}$ of BChE enzyme and $5 \mu \mathrm{L}$ of DTNB reagent to a 96-well microplate, which was kept for 15 min at $30^{\circ} \mathrm{C}$. Then, $5 \mu \mathrm{L}$ of BTChI substrate solution was added to the mixture to start the enzymatic reaction. Absorbances were determined using a microplate reader (EnSpire Multimode Plate Reader, PerkinElmer, Turku, Finland) at $405 \mathrm{~nm}$ for every $45 \mathrm{~s}, 6$ times consecutively at a controlled temperature of $30^{\circ} \mathrm{C}$. The experiments were conducted in triplicate. The rate of enzyme inhibition was calculated using the equation:

Enzyme Inhibition $(\%)=100-\left[\left(\frac{V_{\text {extract }}}{V_{\max }}\right) \times 100\right]$

where $V_{\text {extract }}$ is the rate of change in the colour of the extract sample ( $\Delta \mathrm{abs} / \Delta$ time) and $V_{\max }$ is the maximum rate of change in colour of the blank sample ( $\Delta \mathrm{abs} / \Delta$ time) not containing any inhibitor extract/compound.

For the $\mathrm{IC}_{50}$ study, the dried crude extract of A. serrata and physostigmine pure reference compound were initially dissolved in $12.5 \%$ DMSO and diluted in distilled water to obtain the final concentrations between 1 to $1000 \mu \mathrm{g} / \mathrm{mL}$. No inhibition was detected at the highest concentration of DMSO used (12.5\%). Physostigmine is a known BChE inhibitor compound and was used as reference for comparison purposes.

\subsubsection{Radical scavenging antioxidant activity}

The antioxidant activity of plant extracts was determined using free-radical scavenging effect on the 2,2-diphenyl-1picrylhydrazyl (DPPH) radical with slight modification (Rauter et al., 2012). Methanolic DPPH solution $(100 \mu \mathrm{M})$ was prepared at least a day before analysis, this is to ensure a fully dissolved solution with a stable wavelength measurement. A. serrata extract mixtures were initially dissolved in $12.5 \%$ DMSO and diluted in distilled water to obtain initial concentration of 
$0.5 \mathrm{mg} / \mathrm{mL}$, giving a final test concentration of $25 \mu \mathrm{g} / \mathrm{mL}$. An aliquot of $10 \mu \mathrm{L}$ of $A$. serrata extract was mixed with $190 \mu \mathrm{L}$ of DPPH solution in a clear 96-well microplate. The mixture was shaken vigorously before being kept in dark at room temperature for $40 \mathrm{~min}$. All the test solutions were measured at 517 $\mathrm{nm}$ using a microplate reader. The results were shown as percentage of DPPH inhibition; these values represent the radical scavenging capacity of the extracts. The percentage of DPPH radical scavenging activity (RSA, \%) is calculated as follows:

$\operatorname{RSA}(\%)=\frac{A b s_{\text {blank }}-A b s_{\text {extract }}}{A b s_{\text {blank }}} \times 100$

The Abs blank is the absorbance of DPPH solution without extract after 40 min while Abs extract is the absorbance after 40 min of the DPPH solution containing the extract mixtures.

\subsubsection{Determination of $\mathrm{IC}_{50}$ plant extract concentrations}

The $\mathrm{IC}_{50}$ value of plant extract is the concentration that inhibits $50 \%$ of enzyme activity or causes $50 \%$ RSA. It was estimated from the inhibition/antioxidant results for different extract concentrations. By plotting the \% inhibitions/RSA against the extract concentrations $(\mu \mathrm{g} / \mathrm{mL})$, the IC $\mathrm{I}_{50}$ value was determined through a nonlinear regression analysis using GraphPad Prism 6 trial version (GraphPad Software Inc, La Jolla, CA, USA). The results for $\mathrm{IC}_{50}$ were reported as mean and 95\% confidence interval limits. Physostigmine and ascorbic acid IC $_{50}$ values were also determined, as those are reference compounds for Alzheimer BChE inhibition and antioxidant, respectively. The $\mathrm{IC}_{50}$ of reference compounds are expected to be much lower than those found for A. serrata plant extracts, as they are pure compounds.

\section{Results and discussion}

Section 3.1 presents the results of single factor experiments. Based on these results a fixed temperature of $50{ }^{\circ} \mathrm{C}$ was selected for RSM study presented in Section 3.2, as the temperature of extraction had a minor effect on BChE inhibition between 50 and $70{ }^{\circ} \mathrm{C} \mathrm{(Fig.} \mathrm{3).} \mathrm{Appropriate} \mathrm{ranges} \mathrm{were} \mathrm{chosen}$ for the other extraction variables: A $0.13-0.65 \mathrm{~W} / \mathrm{mL}, \mathrm{t} 1-20$ min, and E 20-80\% (Section 3.2). In Section 3.3, the experimental validation of the optimal conditions predicted by the RSM models is discussed and IC $_{50}$ values were also determined experimentally.

\subsection{Single factor experiments: effects on $B C h E$ inhibition and DPPH RSA activity}

\subsubsection{Effect of the extraction solvent on $\mathrm{IC}_{50}$ of $\mathrm{A}$. serrata} extracts

Solvent screening is one of the significant steps to identify the best solvent for extracting the targeted compound(s) from complex samples. Many researchers have used different solvent system depending for extraction of various type of bioactive compounds (Zhou and Yu, 2004; Alothman et al., 2009; Pintać et al., 2018). This study investigated five generally used solvents for plant extraction including acetone, chloroform, ethyl acetate, methanol, and ethanol, to extract BChE and antioxidant compounds. The $\mathrm{IC}_{50}$ values for each solvent A. serrata extract were compared. Lower $\mathrm{IC}_{50}$ is favourable as it represents $50 \% \mathrm{BChE}$ inhibition or DPPH RSA at a lower concentration. Fig. 1 illustrates that methanol and ethanol were the most efficient solvents to recover anti $\mathrm{BChE}$ and

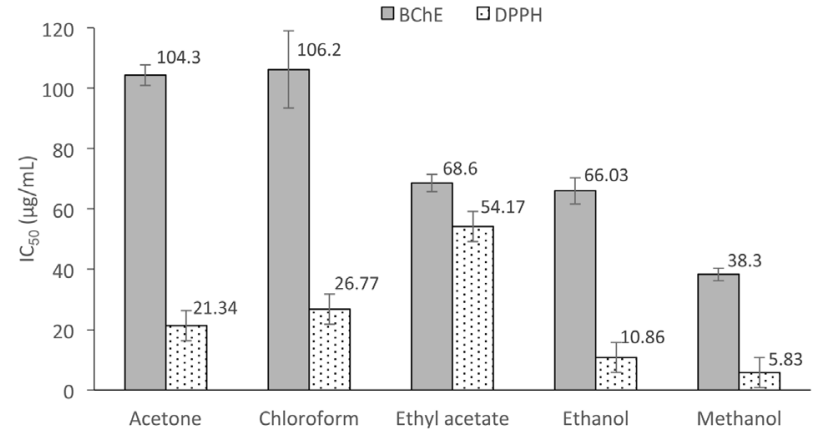

Fig. 1 - Effect of different solvents on $\mathbf{5 0} \%$ inhibition concentrations $\left(\mathrm{IC}_{50}, \mu \mathrm{g}\right.$ extract $/ \mathrm{mL}$ ) for butyrylcholinesterase (BChE) and DPPH radical scavenging activity (RSA) of Aristotelia serrata leaf extracts $(0.52 \mathrm{~W} / \mathrm{mL}$ ultrasound at $50{ }^{\circ} \mathrm{C}$ for 20 min using $1 \mathrm{~g}$ plant mixed with $50 \mathrm{~mL}$ solvent). The error bar represents the values of $95 \%$ confidence interval $(n=3)$.

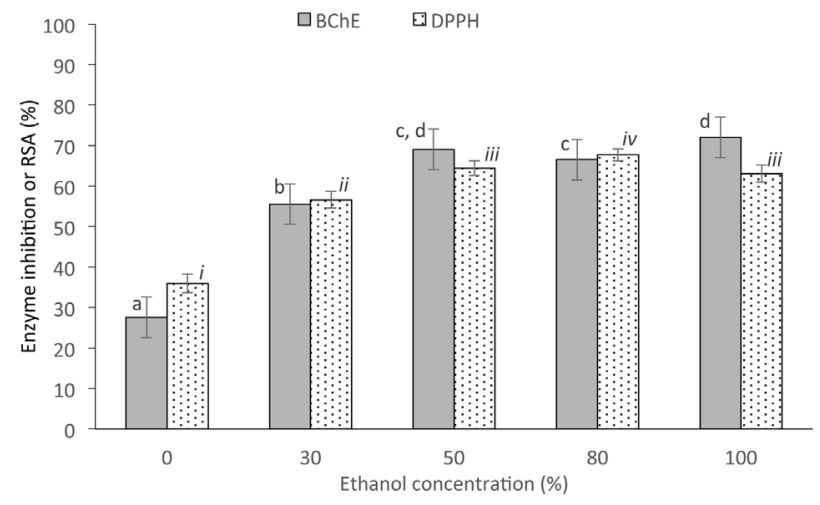

Fig. 2 - Effect of ethanol concentration in water on BChE inhibition and DPPH radical scavenging activity of $A$. serrata leaf extracts $\left(50^{\circ} \mathrm{C}, 0.52 \mathrm{~W} / \mathrm{mL}\right.$ acoustic power density, 10 min; results with different letters for $\mathrm{BChE}$ or roman numbers for RSA are significantly different).

antioxidant related compounds compared to ethyl acetate, chloroform, and acetone. The recovery of any compounds from plant materials is highly influenced by the solubility of the desired compounds in the solvent used in the extraction process (Alothman et al., 2009). The use of methanol and ethanol have been commonly used to extract antioxidative compounds such as phenolics (quercetin) and flavonoids (tannin, catechol, glycoside, anthocyanin) (Yang and Zhang, 2008). Nevertheless, in this study, ethanol is chosen for A. serrata extraction as it is less toxic for human consumption and recommended by the US Food and Drug Administration (Alothman et al., 2009; Tabaraki and Nateghi, 2011). In addition, ethanol can be easily removed by reduced pressure distillation (Wang et al., 2008).

\subsubsection{Effect of ethanol concentration (E)}

The proportions of ethanol-water for the extraction solvent were also investigated. Fig. 2 shows the effect of ethanol concentration at $0 \%, 30 \%, 50 \%, 80 \%$, and $100 \%$ on $\mathrm{BChE}$ inhibition and DPPH RSA of A. serrata extracts extracted for $10 \mathrm{~min}, 0.52$ $\mathrm{W} / \mathrm{mL}$, and $50{ }^{\circ} \mathrm{C}$. The results indicate that the extractions of anti-BChE and antioxidant compounds are favourable at a range of $\mathrm{E}$ from 50 to $100 \%$. The polarity of a solvent is affected by using different ratio of ethanol to water mixtures, as water is a very polar solvent. The combination of water with other 


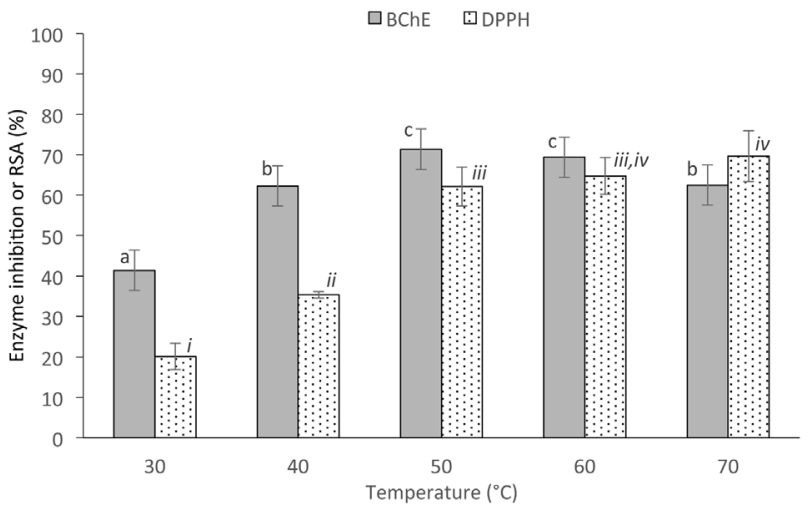

Fig. 3 - Effect of extraction temperature on BChE inhibition and DPPH radical scavenging activity of $A$. serrata leaf extracts using $50 \%$ ethanol for $10 \mathrm{~min}$ at $0.52 \mathrm{~W} / \mathrm{mL}$ acoustic power (Results with different letters for $\mathrm{BChE}$ or roman numbers for RSA).

organic solvents is able to produce moderately polar solvents that have more universal capabilities, ensuring the extraction of many types of compounds (Liu et al., 2000; Chirinos et al., 2007). Furthermore, the existence of water also allowed an effective swelling of the plant, which further increased the surface area for solute-solvent contact (Yang and Zhang, 2008). Ethanol and water mixtures are commonly used for extraction of compounds from plant materials (Alothman et al., 2009). A similar effect was found in the extraction of antioxidant compounds from Rosmarinus officinalis, apple pomace and peanut skins (Albu et al., 2004; Nepote et al., 2005; Wijngaard and Brunton, 2010).

\subsubsection{Effect of extraction temperature}

The suitable temperature range was investigated in this study. The experiments were carried out at temperature from 30 to 70 ${ }^{\circ} \mathrm{C}$ under fixed extraction conditions. Fig. 3 illustrates the effect of temperatures on BChE inhibition and DPPH RSA. It is found that the activities of BChE inhibition and DPPH RSA were gradually increased as the temperature was increased from $30^{\circ} \mathrm{C}$ to $50^{\circ} \mathrm{C}$. However, an insignificant difference of BChE inhibition and DPPH RSA was registered at higher extraction temperatures $\left(\geq 50{ }^{\circ} \mathrm{C}\right)$. The high activities of $\mathrm{BChE}$ inhibition and DPPH RSA at higher temperature mainly contributed various reasons. Firstly, with the increase of temperature, molecular movement accelerated, which increased solubility and desorption rate of anti-BChE and antioxidant related compounds from the cells (Yang et al., 2010). Besides that, at higher temperature, the viscosity, density and surface tension of sample solvent was reduced. As a result, mass transfer will increase by exposing more surface area of the sample to the solvent employed and facilitate solvent penetration deeper into the matrix (Vinatoru, 2001; Ghitescu et al., 2015).

\subsubsection{Effect of extraction time (t)}

Fig. 4 exhibits the effect of $t$ on BChE inhibition and DPPH RSA of A. serrata leaf extracts. A range of extraction times between 2 min and 60 min was studied for constant ultrasound extracting conditions $\left(50 \% \mathrm{E}, 50{ }^{\circ} \mathrm{C}\right.$ and $\left.0.52 \mathrm{~W} / \mathrm{mL}\right)$. For anti-BChE compounds, the results show a gradual increase from $2 \mathrm{~min}$ until $20 \mathrm{~min}$. The extraction produced the maximum inhibition and reached an equilibrium from 20 to $30 \mathrm{~min}$, then dropped after this point. A similar trend is also shown for DPPH RSA. The extraction produced the maximum antioxi-

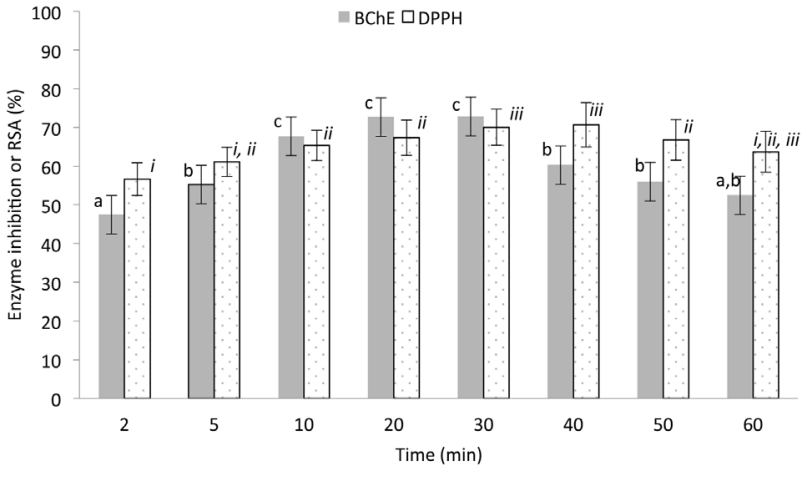

Fig. 4 - Effect of extraction time on BChE inhibition and DPPH radical scavenging activity of $A$. serrata leaf extracts using $50 \%$ ethanol at $50{ }^{\circ} \mathrm{C}$ and $0.52 \mathrm{~W} / \mathrm{mL}$ acoustic power density (Results with different letters for $\mathrm{BChE}$ or roman numbers for RSA are significantly different).

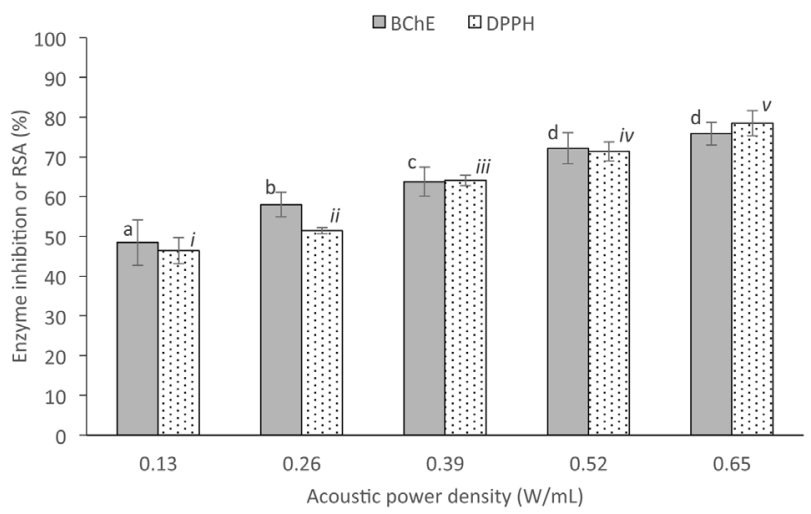

Fig. 5 - Effect of ultrasound acoustic power density on BChE inhibition and DPPH radical scavenging activity of $A$. serrata leaf extracts using $50 \%$ ethanol for $10 \mathrm{~min}$ at $50^{\circ} \mathrm{C}$.

dant activity and reached an equilibrium from 30 to $40 \mathrm{~min}$, then declined after this point.

For both cases, the extraction process occurs in three stages, including a rapid increase, a slow increase/equilibrium, and a decrease stage. During the rapid increase stage, also known as "washing" phenomena, the cell wall of A. serrata leaves powder cracked within a certain period of time as the result of the acoustic cavitation effect, allowing better penetration of the solvent into the cells and enhancing the release of dissolved compounds out of the solid structure of the leaves (Tian et al., 2013). The "slow extraction" may be explained by the decrease in solvent's permeability into A. serrata cell structure, caused by the release of various impurities into the solvent during the washing stage. Besides that, increasing solute content also lowers the diffusion rate and mass transfer from the plant matrix into the solvent (Şahin and Şamli, 2013). The decreasing stage can be observed in BChE inhibition (after $30 \mathrm{~min}$ ) and antioxidant activity (after $40 \mathrm{~min}$ ). This decrease also occured due to the heating effect at $50^{\circ} \mathrm{C}$ of overexposure to ultrasound treatment that caused degradation of the active compounds present in the extracts (Şahin and Şamli, 2013). Therefore, with the negative response at the longer extraction time, it is unneccessary to study beyond this range.

\subsubsection{Effect of acoustic power density (A)}

Fig. 5 exhibits the effect of A on BChE inhibition and antioxidant activity of $A$. serrata extracts. The studied range of $A$ was from $0.13,0.26,0.39,0.52$ and $0.65 \mathrm{~W} / \mathrm{mL}$ and the other 
extraction conditions were fixed at $50 \% \mathrm{E}$, t of $10 \mathrm{~min}$ and temperature at $50^{\circ} \mathrm{C}$. The Figure shows that the higher ultrasound acoustic power density, the better results for both responses, reaching a maximum at $0.52 \mathrm{~W} / \mathrm{mL}$ and $0.65 \mathrm{~W} / \mathrm{mL}$. Ultrasound of $0.52 \mathrm{~W} / \mathrm{mL}$ was chosen for the other experiments as it requires less energy.

It is known that the extraction of various substances from plant material by sonication was achieved by the presence of cavitation bubbles generated by the ultrasonic waves travelling through the solvent. The type and amount of bubbles created are proportional to the amplitude, power or intensity of ultrasonic waves (Chen et al., 2012). The higher the ultrasound energy (amplitude) the greater the production of cavitation bubbles; the collapse of these bubbles are believed to produce high-shear gradients which disrupts the plant cell walls, this enhances the penetration of solvent into solid matrix and accelerates the release of active components into the extraction solvent, leading to a higher extraction efficiency (Tian et al., 2013; Zhao et al., 2013).

\subsection{Experimental results for Box-Behnken design, polynomial models and response surface plots}

The response results obtained for different experimental conditions previously set in the Box-Behnken design are presented in Table 1 , that shows the influence of A (0.13-0.65 $\mathrm{W} / \mathrm{mL}), \mathrm{t}(1-20 \mathrm{~min})$, and $\mathrm{E}(20-80 \%)$ on the BChE inhibition, DPPH RSA, and extract yield of A. serrata extract produced by ultrasound. The $\mathrm{BChE}$ inhibition ranged from $25.84 \pm 5.89 \%$ to $78.28 \pm 4.99 \%$, while antioxidant RSA ranged between 48.54 $\pm 2.01 \%$ to $70.46 \pm 3.35 \%$. As for extraction yield, the values ranged from $28.58 \pm 4.97 \%$ to $58.35 \pm 6.45 \%$.

Based on the experimental results (shown in Table 1), the mathematical model for each response including all the terms was fitted by the statistical software using multiple variable regression. Then, the model was further improved by forward regression and adding the most significant terms, with $p$-values $<0.1000$ (please consult the supplementary file for details of ANOVA analysis). Eqs. (4)-(6) show the quadratic models for BChE inhibition, DPPH RSA and yield in terms of their real values $(A, t, E)$. The quality of the adjustments for each model was given by adj $\mathrm{R}^{2}$ and coefficient of variation (C.V.) and the quality of model predictions was assessed with predicted $\mathrm{R}^{2}$. For $\mathrm{BChE}$ inhibition the fit statistical indicators were 0.79 and $12.01 \%$, for DPPH RSA adj $\mathrm{R}^{2}$ was 0.80 and C.V. $5.06 \%$ and yield adj $R^{2}$ was 0.84 and C.V. $6.99 \%$, demonstrating acceptable models and reliability of the experimental results. In addition, Fig. 6 chart also shows a good correlation between the predicted and experimental data of enzyme inhibition. A high F-value and low p-value are also indicators of good models (and parameters significance). The ANOVA results show p-values of 0.0002, 0.0002, 0.0001 for BChE inhibition, DPPH RSA and yield, respectively. For more detailed information a supplementary data file containing tables with ANOVA results and model fit statistics is supplied.

$B C h E$ inhibition $(\%)=3.610-5.655 * A-0.8334 * t+1.771 * E$

$$
+3.544 * A t-0.01334 * E^{2}
$$

$$
\begin{aligned}
& R S A(\%)=36.37+13.04 * A-0.2361 * t+0.5917 * E \\
& \quad+0.01163 * t E-0.004942 * E^{2}
\end{aligned}
$$

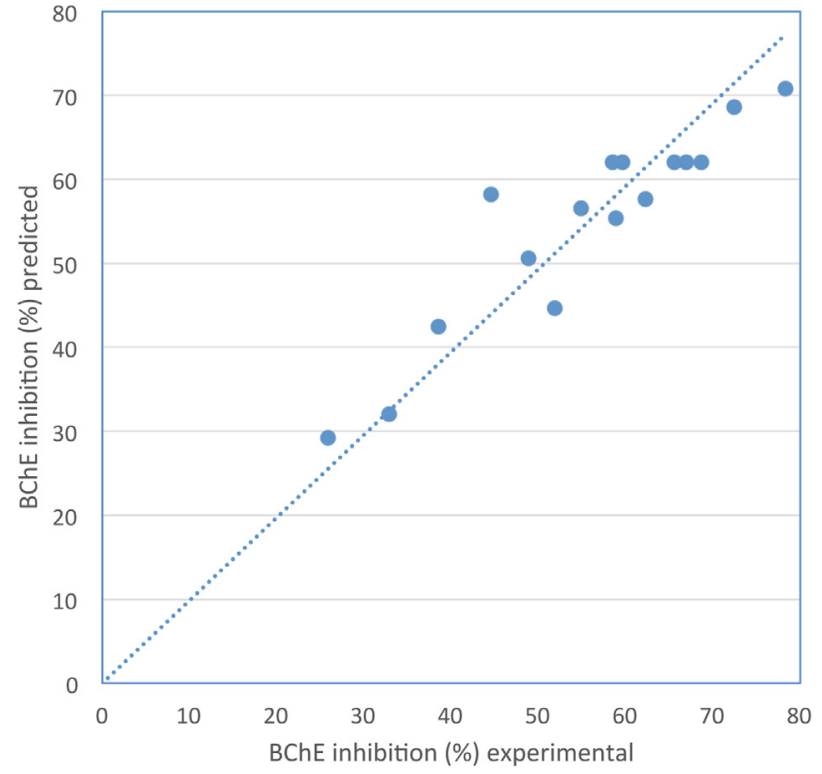

Fig. 6 - Butyrylcholinesterase (BChE) inhibition by Aristotelia serrata leaf extracts: comparison of model predictions with experimental data.

$$
\begin{aligned}
& \text { Yield }(\%)=9.049+9.341 * A+1.800 * t+0.8123 * E \\
& -0.06314 * t^{2}-0.005578 * E^{2}
\end{aligned}
$$

Using the Eqs. (4)-(6), 3D response surface graphs illustrating the effects of two variable on the response were plotted (Fig. 7). Higher slope of the response surface plot indicates a higher effect of the variable in the response. On the contrary, a relatively flat surface plot suggests that the response is not much affected by changes in a specific extraction variable. One graph for each response was plotted. BChE inhibition surface graphs for 10.5 min extraction time is shown in Fig. 7(a). The $\mathrm{BChE}$ inhibition was maximized for higher $\mathrm{A}, \mathrm{E}$ and $\mathrm{t}$. Note for $E$, the value of $B C h E$ inhibition reached an even value when $>60 \%$ ethanol concentration was used. The effect of $t$ and $E$ on the extraction yield of $A$. serrata extracts is shown in chart (b) of Fig. 7. At midpoint of $A(0.39 \mathrm{~W} / \mathrm{mL})$, the extraction yield increased during the first 10 min of extraction. After this time (10 min), the extraction yield reached a plateau in which the difference of yield is low ( $<3 \%)$. According to the slope of the surface response graph, it can be concluded that the highest extraction yield was obtained by using $\mathrm{E}$ of $50-80 \%$ and 10-20 min extraction time. Figure 7, plot (c) show the effect of $t$ and A on DPPH RSA of A. serrata extracts for $50 \%$ ethanol concentration. The DPPH RSA increased with $t$ and A.

\subsection{Experimental validation of optimal conditions estimated by the RSM models}

Based on the RSM models generated, the optimal extraction conditions for BChE inhibition, DPPH RSA, and yield for extraction from A. serrata leaves were determined by setting all the responses to maximum values. The optimum conditions were determined by using the point prediction post analysis tool of Design Expert statistical software. Through this, $\mathrm{A}=0.53$ $\mathrm{W} / \mathrm{mL}, \mathrm{t}=17.12 \mathrm{~min}, \mathrm{E}=74 \%$ were obtained from the Eqs. (4)-(6). Under the optimal conditions, the maximum response values predicted by the models were $70.63 \%$ for $\mathrm{BChE}$ inhibi- 
(a) Time $=10.5 \mathrm{~min}$

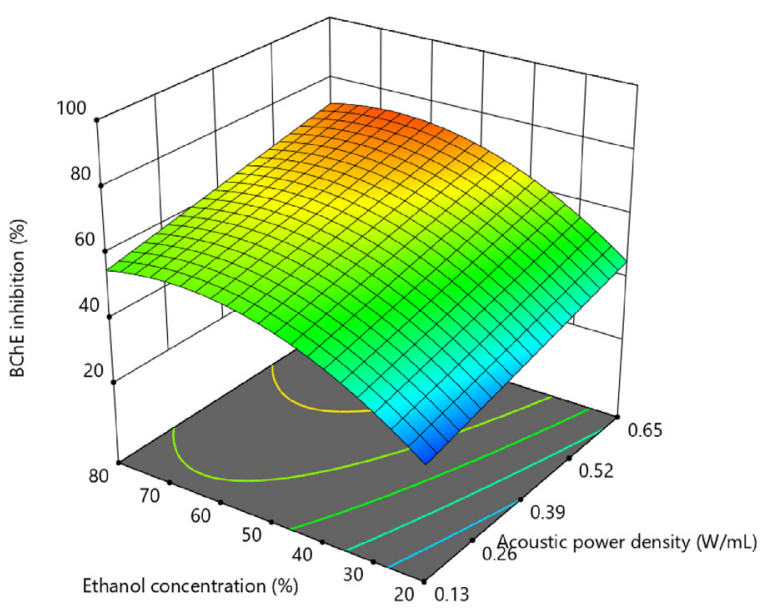

(b) Acoustic energy density $=0.39 \mathrm{~W} / \mathrm{mL}$

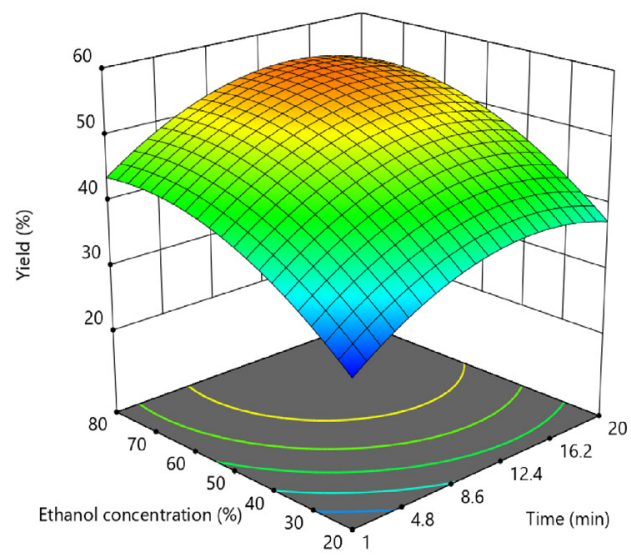

(c) Ethanol concentration $=50 \%$

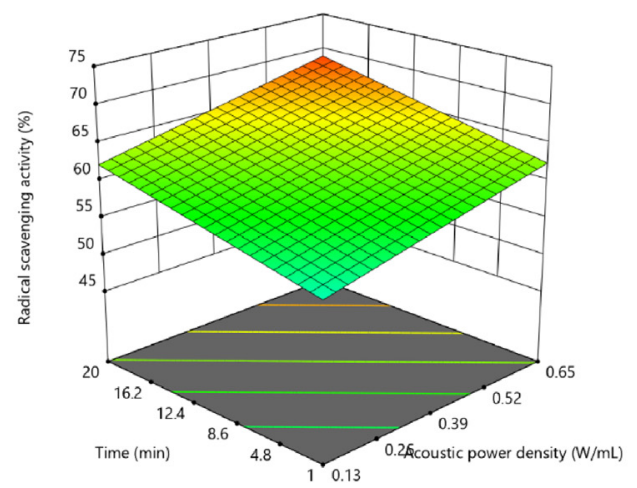

Fig. 7 - Examples of response surface plots showing the effects of acoustic power density, extraction time and ethanol concentration on Aristotelia serrata leaf extracts inhibition of butyrylcholinesterase Alzheimer enzyme for 10.5 min (a), DPPH radical scavenging activity for $50 \%$ ethanol concentration (b), and extraction yield for $0.39 \mathrm{~W} / \mathrm{mL}$ acoustic power density (c).

Table 2 - Optimum ultrasound extraction conditions from A. serrata leaves at $50{ }^{\circ} \mathrm{C}$ for maximum butyrylcholinesterase (BChE) inhibition, radical scavenging activity (RSA) and extraction yield: comparison of values predicted by the model and experimentally determined.

\begin{tabular}{|c|c|c|c|c|}
\hline \multirow{2}{*}{ Optimum conditions for ultrasound extraction } & \multirow{2}{*}{ Responses } & \multicolumn{3}{|l|}{ Maximum values } \\
\hline & & Model prediction & Experimental result ${ }^{\mathrm{a}}$ & Absolute error (\%) \\
\hline Acoustic power density $=0.53 \mathrm{~W} / \mathrm{mL}$ & BChE (\%) & 70.63 & $73.09 \pm 4.39$ & 2.46 \\
\hline Time $=17.12 \mathrm{~min}$ & RSA (\%) & 70.70 & $74.43 \pm 2.46$ & 3.73 \\
\hline Ethanol concentration $=74 \%$ & Yield (\%) & 55.87 & $55.50 \pm 3.22$ & 0.37 \\
\hline
\end{tabular}

tion, $70.70 \%$ for DPPH RSA, and $55.87 \%$ for yield. Table 2 shows the predicted and actual values obtained for BChE inhibition, RSA and yield. The absolute error was below 3.8\%, indicating again the models generated using RSM are adequate to predict BChE inhibition, RSA and yield of A. serrata extracts.

The yield of extraction and $\mathrm{IC}_{50}$ concentrations of the ultrasound optimized and non-optimized A. serrata extracts, Soxhlet extract and reference compounds were also determined and compared (Table 3). With respect to yield, optimization process showed an increase of extraction yield from $47.38 \pm 2.03 \%$ to $55.50 \pm 3.22 \%$, while the yield for conventional Soxhlet extraction for much longer time of $60 \mathrm{~min}$ $\left(78.4{ }^{\circ} \mathrm{C}\right.$ ) was the lowest value $42.63 \pm 2.38 \%$. The optimiza- tion caused a desirable reduction from 66.03 to $26.15 \mu \mathrm{g} / \mathrm{mL}$ in the $\mathrm{IC}_{50}$ of $\mathrm{BChE}$ enzyme inhibition, and a reduction to 5.537 $\mu \mathrm{g} / \mathrm{mL}$ in the $\mathrm{IC}_{50}$ of RSA, which was lower than the ascorbic acid, and implies a higher antioxidant activity of the crude A. serrata extract.

\section{Conclusion}

This study demonstrates that ultrasound assisted extraction was an effective and reliable method for extraction of anti-BChE and antioxidant related compounds from Aristotelia serrata leaves. The quadratic models obtained through RSM were adequate to describe the effect of $\mathrm{A}, \mathrm{t}$, and $\mathrm{E}$ on $\mathrm{BChE}$ 
Table 3 - Yields and IC $_{50}$ concentrations for butyrylcholinesterase (BChE) inhibition and radical scavenging activity (RSA) of A. serrata leaf extracts: comparison of ultrasound optimized extract with ultrasound non-optimized extract, Soxhlet extract and reference compounds for Alzheimer enzyme inhibition and antioxidant activity.

\begin{tabular}{|c|c|c|c|c|c|c|c|}
\hline \multirow[t]{2}{*}{ Extract } & \multirow{2}{*}{$\begin{array}{l}\text { Acoustic power } \\
\text { density (W/mL) }\end{array}$} & \multirow{2}{*}{$\begin{array}{l}\text { Ethanol } \\
\text { conc. (\%) }\end{array}$} & \multirow[t]{2}{*}{ Time (min) } & \multirow[t]{2}{*}{ Temp. $\left({ }^{\circ} \mathrm{C}\right)$} & \multicolumn{2}{|c|}{$\mathrm{IC}_{50}(\mu \mathrm{g} / \mathrm{mL})^{\mathrm{a}}$} & \multirow[t]{2}{*}{ Yield (\%) } \\
\hline & & & & & $\mathrm{BChE}$ & RSA & \\
\hline $\begin{array}{l}\text { Optimized } \\
\text { ultrasound }\end{array}$ & 0.53 & 74 & 17.12 & 50 & 26.15 (23.72-28.83) & $5.537(4.538-6.756)$ & $55.50 \pm 3.22$ \\
\hline $\begin{array}{l}\text { Non-optimized } \\
\text { ultrasound }\end{array}$ & 0.52 & 100 & 20 & 50 & $66.03(61.93-70.40)$ & $10.86(10.08-11.70)$ & $47.38 \pm 2.03$ \\
\hline Soxhlet ${ }^{b}$ & - & 100 & 60 & 78.4 & nd & nd & $42.63 \pm 2.38$ \\
\hline Physostigmine $^{c}$ & & & & & $0.9438(0.8573-1.039)$ & - & - \\
\hline Ascorbic acid ${ }^{c}$ & & & & & - & $12.01(10.23-14.11)$ & - \\
\hline
\end{tabular}

${ }^{a}$ IC $_{50}$ is the plant extract concentration presenting $50 \%$ of BChE inhibition or RSA. The values inside parenthesis are the $95 \%$ confidence interval

b For Soxhlet extraction $100 \%$ ethanol was used for extraction in the proportion of $125 \mathrm{~mL}$ of solvent for $10 \mathrm{~g}$ of A. serrata leaves; nd - not determined.

Physostigmine and ascorbic acid are known BChE inhibitor and antioxidant, respectively, both used as references.

inhibition, DPPH RSA, and extraction yield. The parameters investigated were found to have individual and combined effects for all the responses. Studies involving the chemical analysis of extracts produced under optimum conditions, namely the identification of compounds responsible for biological activities are an important area of future research. In conclusion extracts from $A$. serrata leaves have potential to be used as a complement to approved medication for memory dysfunction or neurodegenerative type diseases such as Alzheimers Disease. The extracts can be taken in the form of a beverage or incorporated into a solid food.

\section{Conflict of interest}

The authors confirm there is no conflict of interest.

\section{Acknowledgements}

PhD Scholarship by Ministry of Higher Education Malaysia, Government of Malaysia is acknowledged. The authors acknowledge "The Biocide ToolBox for New Zealand Manufacturing Exporters", funded by the New Zealand Ministry of Business, Innovation and Employment. Fred Allen (Kiwi Plants Ltd, New Zealand) for supply of plant material.

\section{Appendix A. Supplementary data}

Supplementary material related to this article can be found, in the online version, at doi:https://doi.org/10.1016/j.fbp.2020.10.004.

\section{References}

Adewusi, E.A., Steenkamp, V., 2011. In vitro screening for acetylcholinesterase inhibition and antioxidant activity of medicinal plants from southern Africa. Asian Pac. J. Trop. Med. 4, 829-835, http://dx.doi.org/10.1016/S1995-7645(11)60203-4.

Albu, S., Joyce, E., Paniwnyk, L., Lorimer, J.P., Mason, T.J., 2004. Potential for the use of ultrasound in the extraction of antioxidants from Rosmarinus officinalis for the food and pharmaceutical industry. Ultrason. Sonochem. 11, 261-265, http://dx.doi.org/10.1016/j.ultsonch.2004.01.015.

Alothman, M., Bhat, R., Karim, A.A., 2009. Antioxidant capacity and phenolic content of selected tropical fruits from Malaysia, extracted with different solvents. Food Chem. 115, 785-788, http://dx.doi.org/10.1016/j.foodchem.2008.12.005.
Apel, C., Lyng, J.G., Papoutsis, K., Harrison, S.M., Brunton, N.P., 2020. Screening the effect of different extraction methods (ultrasound-assisted extraction and solid-liquid extraction) on the recovery of glycoalkaloids from potato peels: optimisation of the extraction conditions using chemometric tools. Food Bioprod. Process. 119, 277-286, http://dx.doi.org/10.1016/j.fbp.2019.06.018.

Brooker, S.G., Cooper, R.C., 1961. New Zealand Medicinal Plants, Economic Botany. Heinemann, http://dx.doi.org/10.1007/BF02906757.

Chakraborty, S., Uppaluri, R., Das, C., 2020. Optimization of ultrasound-assisted extraction (UAE) process for the recovery of bioactive compounds from bitter gourd using response surface methodology (RSM). Food Bioprod. Process. 120, 114-122, http://dx.doi.org/10.1016/j.fbp.2020.01.003.

Chen, R., Li, Y., Dong, H., Liu, Z., Li, S., Yang, S., Li, X., 2012. Optimization of ultrasonic extraction process of polysaccharides from Ornithogalum caudatum Ait and evaluation of its biological activities. Ultrason. Sonochem. 19, 1160-1168, http://dx.doi.org/10.1016/j.ultsonch.2012.03.008.

Chirinos, R., Rogez, H., Campos, D., Pedreschi, R., Larondelle, Y., 2007. Optimization of extraction conditions of antioxidant phenolic compounds from mashua (Tropaeolum tuberosum Ruíz \& Pavón) tubers. Sep. Purif. Technol. 55, 217-225, http://dx.doi.org/10.1016/j.seppur.2006.12.005.

Dubey, T., Chinnathambi, S., 2019. Brahmi (Bacopa monnieri): an ayurvedic herb against the Alzheimer's disease. Arch. Biochem. Biophys. 676, 108153, http://dx.doi.org/10.1016/j.abb.2019.108153.

Farlow, M., 2002. A clinical overview of cholinesterase inhibitors in Alzheimer's disease. Int. Psychogeriatrics 14, 93-126, http://dx.doi.org/10.1017/S1041610203008688.

Ghitescu, R.E., Volf, I., Carausu, C., Bühlmann, A.M., Gilca, I.A., Popa, V.I., 2015. Optimization of ultrasound-assisted extraction of polyphenols from spruce wood bark. Ultrasonics Sonochem. 22, 535-541, http://dx.doi.org/10.1016/j.ultsonch.2014.07.013.

Giacobini, E., 2001. Selective inhibitors of butyrylcholinesterase. Drugs \& Aging 18 (12), 891-898.

Greig, N.H., Utsuki, T., Yu, Q., Zhu, X., Holloway, H.W., Perry, T., Lee, B., Ingram, D.K., Lahiri, D.K., 2001. A new therapeutic target in Alzheimer's Disease treatment: attention to butyrylcholinesterase. Curr. Med. Res. Opin. 17, 159-165, http://dx.doi.org/10.1185/0300799039117057.

Hielscher, 2007. UP200S/UP400S: Instruction Manual. Hielscher Ultrasonics GmbH, Teltow, Germany.

Hossain, M.B., Tiwari, B.K., Gangopadhyay, N., O'Donnell, C.P., Brunton, N.P., Rai, D.K., 2014. Ultrasonic extraction of steroidal alkaloids from potato peel waste. Ultrason. Sonochem. 21, 1470-1476, http://dx.doi.org/10.1016/j.ultsonch.2014.01.023.

Huang, S.W., Wang, W., Zhang, M.Y., Liu, Q.B., Luo, S.Y., Peng, Y., Sun, B., Wu, D.L., Song, S.J., 2016. The effect of ethyl acetate 
extract from persimmon leaves on Alzheimer's disease and its underlying mechanism. Phytomedicine 23, 694-704, http://dx.doi.org/10.1016/j.phymed.2016.03.009.

Liu, F.F., Ang, C.Y.W., Springer, D., 2000. Optimization of extraction conditions for active components in Hypericum perforatum using response surface methodology. J. Agric. Food Chem. 48, 3364-3371, http://dx.doi.org/10.1021/jf991086m.

Ma, Y., Yang, Man Wen, Li, X.W., Yue, J.W., Chen, J.Z., Yang, Mei Wen, Huang, X., Zhu, L.L., Hong, F.F., Yang, S.L., 2019. Therapeutic effects of natural drugs on Alzheimer's disease. Front. Pharmacol., http://dx.doi.org/10.3389/fphar.2019.01355.

Majid, H., Silva, F.V.M., 2020. Inhibition of enzymes important for Alzheimer's disease by antioxidant extracts prepared from 15 New Zealand medicinal trees and bushes. J. R. Soc. New Zeal., 1-14, http://dx.doi.org/10.1080/03036758.2020.1741403.

Markesbery, W.R., 1997. Oxidative stress hypothesis in Alzheimer's disease. Free Radic. Biol. Med. 23, 134-147, http://dx.doi.org/10.1016/S0891-5849(96)00629-6.

Nepote, V., Grosso, N.R., Guzmán, C.A., 2005. Optimization of extraction of phenolic antioxidants from peanut skins. J. Sci. Food Agri. 85 (1), 33-38.

Orhan, I., Şener, B., Choudhary, M.I., Khalid, A., 2004 Acetylcholinesterase and butyrylcholinesterase inhibitory activity of some Turkish medicinal plants. J. Ethnopharmacol. 91, 57-60, http://dx.doi.org/10.1016/j.jep.2003.11.016.

Pajk, S., Knez, D., Košak, U., Zorović, M., Brazzolotto, X., Coquelle, N., Nachon, F., Colletier, J.P., Živin, M., Stojan, J., Gobec, S., 2020. Development of potent reversible selective inhibitors of butyrylcholinesterase as fluorescent probes. J. Enzyme Inhib. Med. Chem. 35, 498-505, http://dx.doi.org/10.1080/14756366.2019.1710502.

Pintać, D., Majkić, T., Torović, L., Orčić, D., Beara, I., Simin, N., Mimica-Dukić, N., Lesjak, M., 2018. Solvent selection for efficient extraction of bioactive compounds from grape pomace. Ind. Crops Prod. 111, 379-390, http://dx.doi.org/10.1016/j.indcrop.2017.10.038.

Rambo, D.F., Biegelmeyer, R., Toson, N.S.B., Dresch, R.R., Moreno, P.R.H., Henriques, A.T., 2019. Box-Behnken experimental design for extraction optimization of alkaloids from Erythrina verna Vell. trunk barks and LC Method Validation. Ind. Crops Prod. 133, 250-258,

http://dx.doi.org/10.1016/j.indcrop.2019.03.030.

Rauter, A.P., Branco, I., Lopes, R.G., Justino, J., Silva, F.V.M., Noronha, J.P., Cabrita, E.J., Brouard, I., Bermejo, J., 2007. A new lupene triterpenetriol and anticholinesterase activity of Salvia sclareoides. Fitoterapia 78, 474-481, http://dx.doi.org/10.1016/j.fitote.2007.02.013.

Rauter, A.P., Dias, C., Martins, A., Branco, I., Neng, N.R., Nogueira, J.M., Goulart, M., Silva, F.V.M., Justino, J., Trevitt, C., Waltho, J.P., 2012. Non-toxic Salvia sclareoides Brot. extracts as a source of functional food ingredients: phenolic profile, antioxidant activity and prion binding properties. Food Chem. 132, 1930-1935, http://dx.doi.org/10.1016/j.foodchem.2011.12.028.
Şahin, S., Şamli, R., 2013. Optimization of olive leaf extract obtained by ultrasound-assisted extraction with response surface methodology. Ultrason. Sonochem. 20, 595-602, http://dx.doi.org/10.1016/j.ultsonch.2012.07.029.

Saxton, J.E., 2008. Alkaloids of Aristotelia species. In: Indoles, Part 4 Monoterpenoid Indole Alkaloids 88., pp. 47-62, http://dx.doi.org/10.1002/9780470186954.ch2.

Schelterns, P., Feldman, H., 2003. Treatment of Alzheimer's disease; current status and new perspectives. Lancet Neurol. 2, 539-547.

Tabaraki, R., Nateghi, A., 2011. Optimization of ultrasonic-assisted extraction of natural antioxidants from rice bran using response surface methodology. Ultrason. Sonochem. 18, 1279-1286, http://dx.doi.org/10.1016/j.ultsonch.2011.05.004.

Tian, Y., Xu, Z., Zheng, B., Martin Lo, Y., 2013. Optimization of ultrasonic-assisted extraction of pomegranate (Punica granatum L.) seed oil. Ultrason. Sonochem. 20, 202-208, http://dx.doi.org/10.1016/j.ultsonch.2012.07.010.

Tiwari, P., Kumar, B., Mandeep, K., Kaur, G., Kaur, H., 2011. Phytochemical screening and extraction: a review. Int. Pharm. Sci. 1, 98-106.

Vinatoru, M., 2001. An overview of the ultrasonically assisted extraction of bioactive principles from herbs. Ultrason. Sonochem. 8, 303-313, http://dx.doi.org/10.1016/S1350-4177(01)00071-2.

Wang, J., Sun, B., Cao, Y., Tian, Y., Li, X., 2008. Optimisation of ultrasound-assisted extraction of phenolic compounds from wheat bran. Food Chem. 106, 804-810, http://dx.doi.org/10.1016/j.foodchem.2007.06.062.

Wijngaard, H.H., Brunton, N., 2010. The optimisation of solid-liquid extraction of antioxidants from apple pomace by response surface methodology. J. Food Eng. 96, 134-140, http://dx.doi.org/10.1016/j.jfoodeng.2009.07.010.

Yang, L., Cao, Y.L., Jiang, J.G., Lin, Q.S., Chen, J., Zhu, L., 2010. Response surface optimization of ultrasound-assisted flavonoids extraction from the flower of Citrus aurantium L. var. amara. Engl. J. Sep. Sci. 33, 1349-1355, http://dx.doi.org/10.1002/jssc.200900776.

Yang, Y., Zhang, F., 2008. Ultrasound-assisted extraction of rutin and quercetin from Euonymus alatus (Thunb.) Sieb. Ultrason. Sonochem. 15, 308-313, http://dx.doi.org/10.1016/j.ultsonch.2007.05.001.

Zhao, Z., Xu, X., Ye, Q., Dong, L., 2013. Ultrasound extraction optimization of Acanthopanax senticosus polysaccharides and its antioxidant activity. Int. J. Biol. Macromol. 59, 290-294, http://dx.doi.org/10.1016/j.ijbiomac.2013.04.067.

Zhou, K., Yu, L., 2004. Effects of extraction solvent on wheat bran antioxidant activity estimation. LWT Food Sci. Technol. 37, 717-721, http://dx.doi.org/10.1016/j.lwt.2004.02.008. 